\title{
Sombreamento e substrato na produção de mudas de Lactuca canadensis L.
}

\section{Cárita Rodrigues de Aquino Arantes', Dryelle Sifuentes Pallaoro', Amanda Ribeiro Correa', Elisangela Clarete Camili', Maria de Fátima Barbosa Coelho'}

\author{
'Universidade Federal de Mato Grosso, Programa de Pós-Graduação em Agricultura Tropical \\ Av. Fernando Correa da Costa, n²367,- CEP 78060-900, Cuiabá,- Mato Grosso, Brasil. \\ carita.rodrigues@hotmail.com
}

Recebido em 16.VIII.2018

Aceito em 25.VI.2019

DOI 10.21826/2446-82312019v74e2019005

\begin{abstract}
RESUMO - Avaliou-se a produção de mudas de L. canadensis em níveis de sombreamento e doses de esterco bovino adicionados ao substrato. O delineamento em fatorial 3 x 5 testou três níveis de sombreamento 35, 50 e $70 \%$ e cinco doses de esterco $0,15,30,45$ e $60 \%$. Avaliou-se a porcentagem de emergência e sobrevivência, tempo médio de emergência, comprimento da parte aérea e da raiz, razão entre comprimento da parte aérea e da maior raiz, massa seca da parte aérea e das raízes, número de folhas, diâmetro do colo, teor de clorofila total e índice de qualidade de Dickson. Os sombreamentos de 50 e $70 \%$ favoreceram a germinação e emergência, entretanto para o desenvolvimento de L. canadensis os sombreamentos a 35 e $50 \%$ foram mais eficientes. $\mathrm{O}$ incremento de esterco ao substrato proporcionou melhor crescimento das mudas, em que, a adição de $60 \%$ foi superior as demais doses.
\end{abstract}

Palavras-chave: almeirão roxo, cultivo protegido, esterco bovino

\begin{abstract}
Shading and substrate in the production of Lactuca canadensis L. seedlings. The production of $L$. canadensis seedlings at levels of shading and doses of bovine manure added to the substrate was evaluated. The $3 \times 5$ factorial design tested three levels of shading 35 , 50 and $70 \%$ and five doses of manure $0,15,30,45$ and $60 \%$. It was evaluated the percentage of emergence and survival, mean time of emergence, shoot and root length, ratio between shoot length and largest root, dry mass of shoots and roots, number of leaves, neck diameter, total chlorophyll content and Dickson quality index. The shading of 50 and 70\% favored germination and emergence, however for the development of $L$. canadensis the shading at 35 and $50 \%$ was more efficient. The increase in manure to the substrate gave better growth of the seedlings, in which, the addition of $60 \%$ was superior to the other doses.
\end{abstract}

Keywords: bovine manure, protected crop, purple almeirão

\section{INTRODUÇÃO}

Com o aumento da população mundial e as mudanças para hábitos alimentares mais saudáveis, tem surgido relevante preocupação com a segurança alimentar e a necessidade de um melhor aproveitamento dos vegetais disponíveis para consumo. Neste cenário, espécies de consumo restrito ou local vêm se destacando e, buscando sua valorização, surgiu a denominação Plantas Alimentícias Não Convencionais ou PANC (Kinupp \& Barros 2007), que são aquelas plantas pouco estudadas pela comunidade técnico-científica ou exploradas pela sociedade como um todo.

Essas plantas merecem uma especial atenção devido ao valor nutricional e a facilidade de cultivo, pois a maioria é espontânea, rústica e resistente às adversidades ambientais em que estão inseridas (Kinupp \& Lorenzi 2014). Em geral, apresentam consumo regional ou local, com dificuldade de aceitação pelo consumidor, muitas vezes por não estarem comercialmente organizadas enquanto cadeia produtiva (Brasil 2010).
Dentre elas tem-se a Lactuca canadensis, espécie pertencente à família Asteraceae, cujas sinonímias são Lactuca sagittifolia Elliott e Lactuca canadensis var. obovata Wiegand, conhecida popularmente como almeirão roxo, radite-cote, orelha-de-coelho e almeirão de árvore (Kinupp \& Lorenzi 2014). Para o cultivo desta hortaliça em larga escala, estudos sobre o manejo da cultura são necessários, devido à escassez de informações sobre as práticas agrícolas adequadas durante o processo produtivo.

Assim, entre os fatores que afetam a produção de mudas, a ambiência vegetal é um dos mais importantes, sendo este definido como um conjunto de elementos que compõe as condições micrometeorológicas da área de produção, visando o melhor desenvolvimento das plantas e maior produtividade. Dessa forma, a utilização de ambientes protegidos e/ou telas de sombreamento são ferramentas importantes, pois permitem a utilização dos elementos micrometeorológicos de maneira adequada (Santos et al. 2017).

Outro fator relevante é a escolha do substrato adequado. No caso das hortaliças folhosas em geral, existe a necessidade 
de utilização de substratos de fácil aquisição e que proporcionem a produção de mudas de boa qualidade. $\mathrm{O}$ uso de adubos orgânicos de origem animal, como fonte de nutrientes às plantas e como condicionadores do solo têm se constituído uma alternativa viável, pois reduzem a aplicação de adubos químicos, diminuindo o impacto sobre o meio ambiente (Santos et al. 2010, Frade Júnior et al. 2011).

Segundo Sobrinho et al. (2010), o esterco bovino é tradicionalmente utilizado como fonte orgânica na composição de substratos para produção de mudas de diversas espécies. Assim, objetivou-se avaliar a produção de mudas de $L$. canadensis em diferentes níveis de sombreamento e doses de esterco bovino.

\section{MATERIAL E MÉTODOS}

O experimento foi conduzido no período de agosto a setembro, em Cuiabá, Mato Grosso, latitude 1536’33” S, longitude $56^{\circ} 03^{\prime} 55^{\prime \prime} \mathrm{O}$ e altitude de $145 \mathrm{~m}$. As sementes de Lactuca canadensis, obtidas de plantas matrizes, foram coletadas no ponto de maturidade fisiológica, quando apresentavam coloração preta e dispersão das panículas. No momento da colheita determinou-se o teor de água das sementes em subamostras de $0,2 \mathrm{~g}$, pelo método da estufa a $105 \pm 3{ }^{\circ} \mathrm{C}$ por $24 \mathrm{~h}$, com três repetições (Brasil 2009). $\mathrm{O}$ teor de água médio foi de $10 \%$.

O delineamento experimental adotado foi o inteiramente casualizado em esquema fatorial $3 \times 5$ testando três níveis de sombreamento e cinco doses de esterco bovino curtido, com quatro repetições. Os níveis de sombreamento foram obtidos utilizando-se telas pretas de polietileno com $35 \%, 50 \%$ e $70 \%$ de sombreamento. Os substratos foram compostos pela mistura de substrato comercial para hortaliças (Vivatto Slim ${ }^{\circledR}$ Plus) acrescido de esterco bovino curtido nas proporções de $0 \%, 15 \%, 30 \%, 45 \%$ e $60 \%$ (v:v).

$\mathrm{O}$ substrato comercial utilizado era composto por moinha de carvão vegetal, casca de pinus e turfa, de acordo com informações da embalagem. As características químicas e físicas do substrato comercial e do esterco bovino encontram-se na (Tab. 1).

Após a mistura, os substratos foram distribuídos em bandejas de poliestireno expandido ("isopor") de 128 células com profundidade de $56 \mathrm{~mm}$, largura de $35 \mathrm{~mm}$ e com capacidade de $34,6 \mathrm{~cm}^{3}$ por célula. A semeadura foi feita colocando-se aproximadamente seis sementes por célula, cobrindo as mesmas com uma fina camada de vermiculita expandida (cerca de $2 \mathrm{~mm}$ ) para evitar a exposição direta das sementes ao sol, vento e à água de irrigação. $\mathrm{O}$ desbaste foi realizado aos 14 dias após a semeadura, permanecendo apenas a plântula mais vigorosa por célula. A irrigação foi feita manualmente, com regador, duas vezes ao dia.

Trinta dias após a semeadura, avaliou-se 14 plantas úteis por parcela. As características analisadas foram: porcentagem de emergência de plântulas, seguindo modelo proposto por Labouriau \& Valadares (1976), sendo consideradas emergidas aquelas que apresentavam a parte aérea visível com no mínimo $2 \mathrm{~mm}$ de comprimento; porcentagem de sobrevivência de plântulas, considerando aquelas que sobreviveram do momento do desbaste até a avaliação final; tempo médio de emergência através da equação de Labouriau (1983), observando-se o número de plântulas emergidas diariamente, até a estabilização; comprimento da parte aérea, medindo-se do colo da muda até a extremidade da folha mais nova; comprimento da raiz, medindo-se do colo da muda até a extremidade da maior raiz; razão comprimento da parte aérea/raiz (CPA/CR).

Avaliou-se ainda a massa seca da parte aérea e das raízes, obtidas por meio de pesagem das plantas em balança analítica, após a secagem em estufa com ventilação de ar forçado, por $72 \mathrm{~h} \mathrm{a} 60^{\circ} \mathrm{C}$; número de folhas, pela contagem das folhas completamente expandidas; diâmetro do colo, aferido na região do colo com paquímetro digital; teor de clorofila total, determinado na segunda folha mais nova, utilizando clorofilômetro digital (clorofiLOG CFL1030); e índice de qualidade de Dickson, através da fórmula IQD = [MSP/(H/D + CPA/CR)], em que: (massa seca de planta MSP; razão altura/diâmetro - H/D; comprimento da parte aérea - CPA e comprimento da raiz - CR) (Dickson et al. 1960). Os dados foram submetidos à análise de variância e, quando significativos, realizou-se o teste de Sckott Knott ao nível de $5 \%$ de probabilidade.

\section{RESULTADOS E DISCUSSÃO}

O nível de sombreamento influenciou a porcentagem de emergência e de sobrevivência, tempo médio de emergência e massa seca das raízes de $L$. canadensis. Os níveis de sombreamento $50 \%$ e $70 \%$ proporcionaram os melhores resultados (Tab. 2), entretanto, o fator doses de esterco bovino não foi significativo para essas variáveis. Este fato corrobora com Marcos Filho (2015), que afirma que nos primeiros dias da emergência as plântulas não possuem folhas verdadeiras e capacidade fotossintética, assim são influenciadas principalmente pela temperatura, umidade e oxigênio.

Tabela 1. Análise química e física do substrato comercial (SC) Vivatto Slim ${ }^{\circledR}$ Plus e do esterco bovino curtido (EB). CTC $=$ Capacidade de troca catiônica; $\mathrm{V}=$ Porcentagem de saturação por bases; $\mathrm{MO}$ = Matéria orgânica.

\begin{tabular}{|c|c|c|c|c|c|c|c|c|c|c|c|c|c|}
\hline \multirow[b]{3}{*}{$\mathrm{SC}$} & \multicolumn{2}{|c|}{---- pH ---- } & $\mathrm{P}$ & $\mathrm{K}$ & $\mathrm{Ca}$ & $\mathrm{Mg}$ & $\mathrm{Al}$ & $\mathrm{H}$ & $\mathrm{S}$ & CTC & $\mathrm{V}$ & Sat.H & MO \\
\hline & $\mathrm{H}_{2} \mathrm{O}$ & $\mathrm{CaCl}_{2}$ & \multicolumn{2}{|c|}{$--\left(\mathrm{mg} \mathrm{d}^{-3)}--\right.$} & \multicolumn{5}{|c|}{---------- $\left(\mathrm{cmol}_{\mathrm{c}} \mathrm{dm}^{-3}\right)$---------- } & & \multicolumn{3}{|c|}{-------- (\%) -------- } \\
\hline & 6,6 & 5,8 & 773,3 & 2.690 & 9,9 & 2,32 & 82,9 & 5,05 & 19,2 & 24,3 & 79,2 & 20,8 & 82,9 \\
\hline EB & 6,7 & 5,9 & 795,6 & 3.665 & 2,8 & 1,04 & 79,7 & 0,95 & 13,4 & 14,3 & 93,4 & 6,6 & 79,7 \\
\hline
\end{tabular}


Tabela 2. Porcentagem de emergência (PE) e sobrevivência (PS), tempo médio de emergência (TME) e massa seca das raízes (MSR) de mudas de Lactuca canadensis produzidas em diferentes níveis de sombreamento $(35,50,70 \%)$.

\begin{tabular}{|c|c|c|c|c|}
\hline \multirow{2}{*}{$\begin{array}{l}\text { Níveis de } \\
\text { sombreamento (\%) }\end{array}$} & $\mathrm{PE}$ & PS & \multirow{2}{*}{$\begin{array}{c}\text { TME } \\
\text { (dias) }\end{array}$} & \multirow{2}{*}{$\frac{\text { MSR }}{\left(\mathrm{mg} \mathrm{plântula}^{-1}\right)}$} \\
\hline & \multicolumn{2}{|c|}{$(\%)$} & & \\
\hline 35 & $89,64 * b$ & $87,86 \mathrm{~b}$ & $6,85 \mathrm{a}$ & $7,14 \mathrm{~b}$ \\
\hline 50 & $96,07 \mathrm{a}$ & $94,64 \mathrm{a}$ & $6,49 \mathrm{~b}$ & $11,16 \mathrm{a}$ \\
\hline 70 & $97,50 \mathrm{a}$ & $97,50 \mathrm{a}$ & $6,25 \mathrm{~b}$ & $11,64 \mathrm{a}$ \\
\hline
\end{tabular}

*Médias seguidas de mesma letra, na coluna, não diferem estatisticamente entre si, pelo teste de Scott Knott ao nível de 5\% de significância.

Os menores valores de emergência e sobrevivência das plântulas de L. canadensis sob telado de $35 \%$ de sombreamento podem estar relacionados à sensibilidade a altas temperaturas (Tab. 2). Esta espécie é originária de regiões frias do continente Norte Americano (Lebeda et al. 2012), assim a elevada temperatura da Baixada Cuiabana, local de condução do experimento, pode ter ocasionado a redução na emergência e sobrevivência das plântulas em condições ambientais menos favoráveis.

Para o comprimento e massa seca da parte aérea, número de folhas e clorofila total, a redução no nível de sombreamento foi acompanhada pelo acréscimo no desenvolvimento das mudas (Tab. 3). Essa tendência também pode ser observada na relação comprimento da parte aérea e da raiz (CPA/CR) uma vez que a razão ficou próxima a um, indicando maior equilíbrio na distribuição de fotoassimilados e no desenvolvimento das mudas. Tais diferenças entre os níveis de sombreamento foram significativas principalmente em substratos com doses de esterco bovino superiores a $30 \%$.

Entretanto em estudos com rúcula (Eruca sativa L.) em Cáceres-MT, Costa et al. (2011) constataram que a produção em campo aberto apresentou valores aceitáveis, porém, sob tela preta de $50 \%$, houve incremento na produção em cerca de $43 \%$, além da antecipação da colheita. Semelhantemente, Santana et al. (2009) observaram que a tela de sombreamento preta de $50 \%$ proporcionou maior acúmulo de massa fresca em alface-roxa. De acordo com Guerra et al. (2017) os incrementos em produtividade são devido ao maior número de folhas fotossinteticamente ativas, o que favorece o acúmulo individual de massa fresca, resultado da alteração dos comprimentos de onda e da temperatura.

Avaliando o desdobramento de cada nível de sombreamento nas doses de esterco bovino os maiores resultados de comprimento das raízes e diâmetro do colo ocorreram nas mudas sob tela de sombreamento de $35 \%$ e $50 \%$ respectivamente, ambas no substrato com $30 \%$ de esterco bovino (Tab. 3). De acordo com Mota et al. (2013), em ambientes com maior intensidade luminosa há redução da disponibilidade hídrica para as raízes das plantas devido a maior evaporação da água do substrato, forçando a planta a translocar mais assimilados para o sistema radicular, isto resulta em maior crescimento das raízes para a absorção de água nas camadas mais profundas do substrato.
Quanto ao índice de qualidade de Dickson, não houve diferença entre os níveis de sombreamento para as doses $0 \%, 15 \%$ e $60 \%$ de esterco bovino. Na dose de $30 \%$ e $45 \%$ os melhores resultados foram observados nas mudas a $50 \%$ e $35 \%$ e $50 \%$ de sombreamento respectivamente (Tab. 3). Estudando as espécies Mimosa caesalpiniifolia Benth. e Sterculia foetida L., Câmara \& Endres (2008) concluíram que o sombreamento a $50 \%$ possibilitou o melhor desenvolvimento vegetativo das mudas. Na fase de produção de mudas de hortaliças a proteção com telas de sombreamento atenua os efeitos da radiação direta e diminui os danos aos tecidos das plantas em estado juvenil, o que propicia melhores condições para a formação das mudas, fase essencial para o sucesso das plantas no canteiro de produção e, ainda promove condições adequadas de cultivo em diferentes épocas do ano (Costa et al. 2015).

Observando as doses de esterco bovino, os maiores valores de comprimento e massa seca da parte aérea, diâmetro do colo e clorofila total ocorreram principalmente nas mudas em substrato com $30 \%, 45 \%$ e $60 \%$ de esterco bovino (Tab. 3). A disponibilização de nutrientes, através da decomposição do esterco bovino, principalmente de nitrogênio, possibilita o incremento na parte aérea das mudas por promover maior capacidade fotossintética e aumento do acúmulo de massa nas plantas (Marques et al. 2010).

Além disso, valores superiores de diâmetro do colo podem ser associados à formação de mudas mais vigorosas e menos susceptíveis ao tombamento. De acordo com Camargo et al. (2011), essa característica é a mais indicada para inferir sobre a capacidade de sobrevivência das mudas a campo.

No comprimento da raiz e relação comprimento da parte aérea e raiz, nas mudas sob $50 \%$ e $70 \%$ de sombreamento, não houve diferença entre as doses de esterco bovino. Entretanto, para as mudas a $35 \%$ de sombreamento o maior comprimento ocorreu no substrato com $30 \%$ de esterco bovino e a melhor relação CPA/CR foi observada naquelas com $45 \%$ e $60 \%$ de esterco (Tab. 3 ).

Para o número de folhas e índice de qualidade de Dickson, em geral, as mudas em substrato com $45 \%$ e $60 \%$ de esterco bovino foram superiores (Tab. 3). Em mudas de Cichorium intybus L., Pereira et al. (2012) observaram que a utilização de composto orgânico constituído por resíduo bovino e de milho, gerou aumento no número de folhas. Os 
Tabela 3. Comprimento da parte aérea (CPA) e da raiz (CR), razão comprimento da parte aérea e da raiz (CPA/CR), massa seca da parte aérea (MSPA), número de folhas (NF), diâmetro do colo (DC), teor de clorofila total (CT) e índice de qualidade de Dickson (IQD) de mudas de Lactuca canadensis, cultivadas em diferentes níveis de sombreamento e doses de esterco bovino acrescidas ao substrato comercial

\begin{tabular}{|c|c|c|c|c|c|}
\hline \multirow{3}{*}{$\begin{array}{l}\text { Níveis de } \\
\text { sombreamento (\%) }\end{array}$} & \multicolumn{5}{|c|}{ Doses de esterco (\%) } \\
\hline & 0 & 15 & 30 & 45 & 60 \\
\hline & \multicolumn{5}{|c|}{ CPA (cm plântula ${ }^{-1}$ ) } \\
\hline 35 & $5,36 * \mathrm{bC}$ & $6,57 \mathrm{aB}$ & $8,58 \mathrm{aA}$ & $9,03 \mathrm{aA}$ & $8,25 \mathrm{aA}$ \\
\hline 50 & $5,85 \mathrm{bB}$ & $6,34 \mathrm{aB}$ & $7,87 \mathrm{aA}$ & $7,70 \mathrm{bA}$ & $7,35 \mathrm{bA}$ \\
\hline \multirow[t]{2}{*}{70} & $6,64 \mathrm{aA}$ & $6,06 \mathrm{aA}$ & $6,09 \mathrm{bA}$ & $6,87 \mathrm{bA}$ & $6,78 \mathrm{bA}$ \\
\hline & \multicolumn{5}{|c|}{ CR (cm plântula $\left.{ }^{-1}\right)$} \\
\hline 35 & $9,27 \mathrm{aB}$ & $9,48 \mathrm{aB}$ & $21,06 \mathrm{aA}$ & $8,54 \mathrm{aB}$ & $7,84 \mathrm{aB}$ \\
\hline 50 & $10,19 \mathrm{aA}$ & $8,95 \mathrm{aA}$ & $10,41 \mathrm{bA}$ & $9,42 \mathrm{aA}$ & $9,16 \mathrm{aA}$ \\
\hline \multirow[t]{2}{*}{70} & $9,37 \mathrm{aA}$ & $9,41 \mathrm{aA}$ & $9,68 \mathrm{bA}$ & $9,04 \mathrm{aA}$ & $8,54 \mathrm{aA}$ \\
\hline & \multicolumn{5}{|c|}{$\mathrm{CPA} / \mathrm{CR}$} \\
\hline 35 & $0,58 \mathrm{aB}$ & $0,69 \mathrm{aB}$ & $0,56 \mathrm{aB}$ & $1,06 \mathrm{aA}$ & $1,06 \mathrm{aA}$ \\
\hline 50 & $0,59 \mathrm{aA}$ & $0,71 \mathrm{aA}$ & $0,76 \mathrm{aA}$ & $0,82 \mathrm{bA}$ & $0,81 \mathrm{bA}$ \\
\hline \multirow[t]{2}{*}{70} & $0,71 \mathrm{aA}$ & $0,65 \mathrm{aA}$ & $0,63 \mathrm{aA}$ & $0,77 \mathrm{bA}$ & $0,80 \mathrm{bA}$ \\
\hline & \multicolumn{5}{|c|}{ MSPA (mg plântula ${ }^{-1}$ ) } \\
\hline 35 & $12,40 \mathrm{aB}$ & $16,50 \mathrm{aB}$ & $28,33 \mathrm{aA}$ & $36,62 \mathrm{aA}$ & $26,26 \mathrm{aA}$ \\
\hline 50 & $17,78 \mathrm{aB}$ & $19,27 \mathrm{aB}$ & $29,82 \mathrm{aA}$ & $35,97 \mathrm{aA}$ & $28,99 \mathrm{aA}$ \\
\hline \multirow[t]{2}{*}{70} & $16,30 \mathrm{aB}$ & $14,37 \mathrm{aB}$ & $13,84 \mathrm{bB}$ & $18,84 \mathrm{bA}$ & $22,95 \mathrm{aA}$ \\
\hline & \multicolumn{5}{|c|}{$\mathrm{NF}$} \\
\hline 35 & $2,42 \mathrm{bD}$ & $2,94 \mathrm{aC}$ & $3,38 \mathrm{bB}$ & $3,75 \mathrm{aA}$ & $3,95 \mathrm{aA}$ \\
\hline 50 & $2,93 \mathrm{aC}$ & $3,00 \mathrm{aC}$ & $3,67 \mathrm{aB}$ & $3,77 \mathrm{aB}$ & $4,00 \mathrm{aA}$ \\
\hline \multirow[t]{2}{*}{70} & $2,96 \mathrm{aB}$ & $2,93 \mathrm{aB}$ & $3,00 \mathrm{cB}$ & $3,32 \mathrm{bA}$ & $3,55 \mathrm{bA}$ \\
\hline & \multicolumn{5}{|c|}{ DC (mm plântula $\left.{ }^{-1}\right)$} \\
\hline 35 & $1,94 \mathrm{aB}$ & $2,35 \mathrm{aB}$ & $2,71 \mathrm{bA}$ & $3,08 \mathrm{aA}$ & $2,72 \mathrm{aA}$ \\
\hline 50 & $2,24 \mathrm{aB}$ & $2,33 \mathrm{aB}$ & $3,46 \mathrm{aA}$ & $2,82 \mathrm{aA}$ & $3,30 \mathrm{aA}$ \\
\hline \multirow[t]{2}{*}{70} & $2,09 \mathrm{aB}$ & $1,93 \mathrm{aB}$ & $1,99 \mathrm{cB}$ & $2,55 \mathrm{aA}$ & $3,11 \mathrm{aA}$ \\
\hline & \multicolumn{5}{|c|}{ CT $(\%)$} \\
\hline 35 & $24,02 \mathrm{bC}$ & $29,06 \mathrm{aB}$ & $32,19 \mathrm{aA}$ & $33,44 \mathrm{aA}$ & $33,39 \mathrm{aA}$ \\
\hline 50 & $28,46 \mathrm{aB}$ & $30,34 \mathrm{aB}$ & $33,48 \mathrm{aA}$ & $34,55 \mathrm{aA}$ & $33,90 \mathrm{aA}$ \\
\hline \multirow[t]{2}{*}{70} & $27,43 \mathrm{aB}$ & $28,10 \mathrm{aB}$ & $29,06 \mathrm{bA}$ & $30,96 \mathrm{bA}$ & $30,69 \mathrm{bA}$ \\
\hline & \multicolumn{5}{|c|}{ IQD } \\
\hline 35 & $4,74 \mathrm{aB}$ & $6,32 \mathrm{aB}$ & $7,05 \mathrm{bB}$ & $17,79 \mathrm{aA}$ & $14,89 \mathrm{aA}$ \\
\hline 50 & $6,79 \mathrm{aB}$ & $8,06 \mathrm{aB}$ & $14,00 \mathrm{aA}$ & $14,66 \mathrm{aA}$ & $13,59 \mathrm{aA}$ \\
\hline 70 & $5,80 \mathrm{aB}$ & $4,56 \mathrm{aB}$ & $4,15 \mathrm{bB}$ & $7,36 \mathrm{bB}$ & $10,62 \mathrm{aA}$ \\
\hline
\end{tabular}

*Médias seguidas de mesma letra, minúscula na coluna e maiúscula linha, não diferem estatisticamente entre si, pelo teste de Scott Knott ao nível de $5 \%$ de significância.

autores sugerem ainda que o composto orgânico fornece nutrientes, de forma gradual e equilibrada, possibilitando o melhor desenvolvimento das mudas.

Quanto maior o valor do índice de qualidade de Dickson, melhor a qualidade da muda produzida uma vez que este alia diversos parâmetros biométricos das plantas (Caldeira et al. 2012), sendo assim, as maiores doses de esterco bovino adicionadas ao substrato, $45 \%$ e $60 \%$, possibilitaram o melhor desenvolvimento e a formação de mudas mais vigorosas, principalmente quando combinadas ao sombreamento a $35 \%$ ou $50 \%$ (Tab. 3). Segundo Sá et al. (2013), o uso de produtos orgânicos na composição dos substratos para produção de mudas melhora as características físicas, químicas e biológicas, criando um ambiente favorável ao desenvolvimento inicial das mudas e promovendo respostas satisfatórias de crescimento.

O substrato comercial possui elevada saturação por hidrogênio $(20,8 \%)$ quando comparado ao esterco bovino $(6,6 \%)$ (Tab. 1); portanto, com o aumento na proporção de esterco bovino, em substituição a parte do substrato comercial, ocasionará redução na quantidade de $\mathrm{H}^{+}$. Isso pode ser confirmado pelo menor valor de saturação por bases (V\%) no substrato comercial, indicando maior adsorção de hidrogênio aos colóides, em substituição aos 
cátions de cálcio, magnésio e potássio. Deste modo, a adição de esterco bovino propiciou a formação de um substrato com maior fertilidade.

Para o processo de germinação e emergência de plântulas de L. canadensis, maiores níveis de sombreamento são recomendados $(50 \%$ e $70 \%)$, pois, possibilitaram maior porcentagem de emergência e sobrevivência, além de reduzirem o tempo médio de emergência (Tab. 2). No entanto, após esse processo inicial do desenvolvimento, a utilização de tela com menor densidade (35\% e 50\%) gerou mudas com maior comprimento e massa seca da parte aérea, melhor equilíbrio de crescimento da parte aérea/raiz (CPA/CR), maior número de folhas, teor de clorofila total e, portanto, mudas mais vigorosas (IQD) (Tab. 3).

O sombreamento a $50 \%$ ou $70 \%$ favorece a porcentagem de germinação, emergência e sobrevivência e o tempo médio de emergência de $L$. canadensis, porém os sombreamentos 35 ou $50 \%$ proporcionarem melhor crescimento das mudas. As maiores doses de esterco bovino, $45 \%$ e $60 \%$, adicionadas ao substrato comercial, proporcionam o melhor desenvolvimento das mudas de $L$. canadensis.

\section{REFERÊNCIAS}

Brasil. Ministério da Agricultura, Pecuária e Abastecimento 2009. Regras para análise de sementes. Ministério da Agricultura, Pecuária e Abastecimento. Secretaria de Desenvolvimento Agropecuário e Cooperativismo, Brasília. 399p. http://www.agricultura.gov. br/assuntos/insumos-agropecuarios/arquivos-publicacoesinsumos/2946_regras_analise_sementes.pdf

Brasil. Ministério da Agricultura, Pecuária e Abastecimento 2010. Manual de hortaliças não-convencionais. Ministério da Agricultura, Pecuária e Abastecimento. Secretaria de Desenvolvimento Agropecuário e Cooperativismo, Brasília. 92 p. http://www.abcsem.com.br/docs/ manual_hortalicas_web.pdf

Caldeira, M.V.W., Delarmelina, W.M., Lübe, S.G., Gomes, D.R., Gonçalves, E.O. \& Alves, A. F. 2012. Biossólido na composição de substrato para a produção de mudas de Tectona grandis. Floresta 42(1):77-84. http://dx.doi.org/10.5380/rf.v42i1.26302

Câmara, C.A. \& Endres, L. 2008. Desenvolvimento de mudas de duas espécies arbóreas: Mimosa caesalpiniifolia Benth. e Sterculia foetida L. sob diferentes níveis de sombreamento em viveiro. Floresta 38(1):43-51. http://dx.doi.org/10.5380/rf.v38i1.11026

Camargo, R.C., Pires, S.C., Maldonado, A.C., Carvalho, H.P. \& Costa, T.R. 2011. Avaliação de substratos para a produção de mudas de pinhão-manso em sacolas plásticas. Revista Trópica 5(1):31-38. http://www.periodicoseletronicos.ufma.br/index.php/ccaatropica/ article/view/292/310

Costa, C.M.F., Seabra Júnior, S., Arruda, G.R. \& Souza, S.B.S. 2011. Desempenho de cultivares de rúcula sob telas de sombreamento e campo aberto. Semina: Ciências Agrárias 32(1):93-102. http://www. uel.br/revistas/uel/index.php/semagrarias/article/viewFile/3808/7184

Costa, E., Santo, T.L.E., Silva, A.P., Silva, L.E., Oliveira, L.C., Benett, C.G.S. \& Benett, K.S.S. 2015. Ambientes e substratos na formação de mudas e produção de frutos de cultivares de tomate cereja. Horticultura Brasileira 33(1):110-118. http://www.scielo.br/scielo. php?pid=S0102-05362015000100110\&script $=$ sci_abstract\&tlng $=$ pt

Dickson, A., Leaf, A.L. \& Hosner, J.F. 1960. Quality appraisal of white spruce and white pine seedling stock in nurseries. The Forestry Chronicle 36(1):10-13. http://pubs.cif-ifc.org/doi/pdf/10.5558/tfc36010-1

Frade Junior, E.F., Araújo, J.A., Silva, S.B., Moreira, J.G. V. \& Souza, L.P. 2011. Substratos de resíduos orgânicos para produção de mudas de ingazeiro (Inga edulis Mart) no Vale do Juruá-Acre. Enciclopédia Biosfera 7(13):959-969. http://www.conhecer.org. br/enciclop/2011b/ciencias\%20agrarias/substratos\%20de $\% 20$ residuos.pdf

Guerra, A.M.N.M., Costa, A.C.M. \& Tavares, P.R.F. 2017. Atividade fotossintética e produtividade de alface cultivada sob sombreamento. Revista Agropecuária Técnica 38(3):125-132. http://www.periodicos. ufpb.br/ojs/index.php/at/article/view/29246/18586

Kinupp, V.F. \& Barros, I.B.I. 2007. Riqueza de Plantas Alimentícias Não Convencionais na Região Metropolitana de Porto Alegre, Rio Grande do Sul. Revista Brasileira de Biociências 5(1):63-65. http://www. ufrgs.br/seerbio/ojs/index.php/rbb/article/viewFile/92/88

Kinupp, V.F. \& Lorenzi, H. 2014. Plantas alimentícias não convencionais (PANC) no Brasil: guia de identificação, aspectos nutricionais e receitas ilustradas. Plantarum, Porto Alegre. $621 \mathrm{p}$.

Labouriau, L.G. 1983. A germinação das sementes. Secretaria Geral da Organização dos Estados Americanos, Washington. 173p.

Labouriau, L.G. \& Valadares, M.E.B. 1976. On the germination of seeds Calotropis procera (Ait.) Ait.f. Anais da Academia Brasileira de Ciências 48(2): 263-284. https://scholar.google.com/scholar_lookup ?title $=$ On + the + germination + of + seeds + of + Calotropis + procera $+(A$ it.)+Ait.f\&author $=$ Labouriau + LG\&author $=$ Valadares + MEB\&pub lication_year $=1976 \&$ journal $=A n+A c a d+B r a s+$ Cienc $\&$ volume $=4$ 8 \&pages $=263-84$

Lebeda, A., Doležalová, I. \& Novotná, A. 2012. Wild and weedy Lactuca species, their distribution, ecogeography and ecobiology in USA and Canada. Genetic Resources and Crop Evolution 59(8):1805-1822. https://link.springer.com/article/10.1007/s10722-012-9805-y

Marcos Filho, J. 2015. Fisiologia de sementes de plantas cultivadas. Associação Brasileira de Tecnologia de Sementes, Londrina. 660p.

Marques L.F., Medeiros D.C., Coutinho O.L., Marques L.F., Medeiros, C.B. \& Vale L.S. 2010. Produção e qualidade da beterraba em função da adubação com esterco bovino. Revista Brasileira de Agroecologia 5(1):24-31. http://orgprints.org/25018/1/Marques_ Produ $\% \mathrm{C} 3 \% \mathrm{~A} 7 \% \mathrm{C} 3 \% \mathrm{~A} 30 . \mathrm{pdf}$

Mota, L.H.S., Scalon, S.P.Q. \& Mussury, R.M. 2013. Efeito do condicionamento osmótico e sombreamento na germinação e no crescimento inicial das mudas de angico (Anadenanthera falcata Benth. Speg.). Revista Brasileira de plantas medicinais 14(4):655-653. http://www.scielo.br/scielo.php?pid=S1516$05722013000500005 \&$ script $=$ sci_abstract\&tlng $=$ pt

Pereira, D.C., Grutzmacher, P., Bernardi, F.H., Mallmann, L.S., Costa, L. A. M. \& Costa, M. S. S. M. 2012. Produção de mudas de almeirão e cultivo no campo, em sistema agroecológico. Revista Brasileira de Engenharia Agrícola e Ambiental 16(10):1100-1106. http://dx.doi. org/10.1590/S1415-43662012001000010

Sá, F.V.S., Mesquita, E.F., Bertino, A.M.P., Silva, G.A. \& Costa, J.D. 2013. Biofertilizantes na produção hidropônica de mudas de mamoeiro. Revista Verde de Agroecologia e Desenvolvimento Sustentável 8(3):109-116. http://www.gvaa.com.br/revista/index.php/RVADS/ article/view/2272

Santana, C.V.S., Almeida, A. C. \& Turco, S. H. N. 2009. Produção de alface roxa em ambientes sombreados na região do submédio São Francisco-BA. Revista Verde 4(3): 01-06. https://www.gvaa.com. br/revista/index.php/RVADS/article/view/187/187

Santos, J.F., Grangeiro, J.I.T. \& Oliveira, M.E.C.O. 2010. Produção da cultura da mamoneira em função da fertilização com cama de galinha. Engenharia Ambiental 7(1):169-180. http://ferramentas.unipinhal. edu.br/engenhariaambiental/viewarticle.php?id=374

Santos, T.V., Lopes, T.C., Silva, A.G., Paula, R.C.M., Costa, E. \& Binotti, F.F.S. 2017. Produção de mudas de maracujá amarelo com diferentes materiais refletores sobre bancada. Revista de Agricultura Neotropical 4(4):26-32. http://periodicosonline.uems.br/index.php/agrineo/article/ view/1781/2038

Sobrinho, S.P., Luz, P.B, Silveira, T.L.S., Ramos, D.T., Neves, L.G. \& Barelli, M.A.A. 2010. Substratos na produção de mudas de três espécies arbóreas do cerrado. Agrária 5(2):238-243. http://dx.doi. org/10.5039/agraria.v5i2a741 